\title{
New control scheme for synchronization of a photovoltaic system to a three-phase grid to attenuate the harmonics of currents caused by distorted grid voltage
}

\author{
Ismail Boukhechem ${ }^{1}$, Ahcen Boukadoum², Lahcene Boukelkoul ${ }^{3}$, \\ Houssam Eddine Medouce ${ }^{4}$, Rima Lebied $^{5}$ \\ 1,2,3,5 Department of Electrical, Electrotechnical Laboratory, University of August 20 Skikda, Algeria \\ ${ }^{4}$ Department of Electrical, Universitas Frères Mentouri, Algeria
}

\begin{tabular}{l} 
Article Info \\
\hline Article history: \\
Received Dec 22, 2019 \\
Revised Feb 19, 2020 \\
Accepted April 15, 2020 \\
\hline Keywords: \\
Direct power control (DPC) \\
Distorted grid voltage \\
Grid synchronization \\
Photovoltaic (PV) system
\end{tabular}

\begin{abstract}
This study presents a new scheme of control for the synchronization of a photovoltaic (PV) system with a three-phase grid without a line sensor. The approach of the proposed synchronization technique is developed to extract the maximum of PV energy and inject it in the network for various conditions of voltage, and to ensure that the currents injected into the three-phase network emulate the wished sinusoidal forms even when the mains grid voltage is no longer ideal. This paper introduces a new technique of synchronization and elimination of the disturbances created by the distorted tension based on the direct power control without voltage sensors (VF_DPC) with the help of second-order generalized integrator (SOGI) associated with a self-tuning filter (STF) to extract the fundamental virtual flux. The simulation of the proposed system is realized in MATLAB/Simulink environment.
\end{abstract}

This is an open access article under the CC BY-SA license.

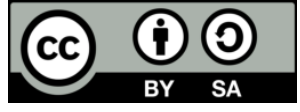

\section{Corresponding Author:}

Ismail Boukhechem,

Department of Electrical, Electrotechnical Laboratory,

University of August 20 Skikda,

B.P.26 route d'El-HadaiekSkikda 21000 Algeria ‘Skikda, Algeria.

Email: sameu25@gmail.com

\section{INTRODUCTION}

The photovoltaic (PV) energy has grown at an annual average of $60 \%$ during the last five years, This growth activated also the evolution of the conventional power converters, inverters connected to the grid becoming more complex in topology, allowing the increase in efficiency and power extraction of modules and reliability without impact on the costs [1]. The PV system connected to the grid represent more than $99 \%$ of the installed PV systems compared to the autonomous PV systems [1]. The efficiency of the PV system connected to the grid is estimated by guaranteeing that the currents injected are sinusoidal and by obtaining a unity power factor (UPF). In a grid-connected photovoltaic system (GCPVS), the PV power varies according to the operating conditions, Such as illumination, temperature, angle of incidence of the light and reduction of sun transmission on module glass and shading [2-5]. These factors were studied in detail in literature and the authors presented diagnostic methods to estimate the reduction in PV power.

Maximum power point tracking (MPPT) is an important problem in PV systems. In literature, several control algorithms were proposed on (MPP), such as Perturb and Observe (P\&O), INC, corrugated and correlation techniques, dual full slip mode $[6,7]$. The $\mathrm{P} \& \mathrm{O}$ method is the most used algorithm because of its implantation simplicity. This method is based on the disturbance of the operating voltage and the major inconveniences of this method are the oscillations around the MPP and the power losses on these points[8]. The constant voltage method is based on an approximate constant report between Vmpp and the open-circuit 
voltage, but their implementation is generally more complicated, which limits their use in real-time applications.

Nowadays, the application of grid-connected PV systems (GCPVS) is widely preferred to the autonomous PV systems [9, 10]. The capacity of the photovoltaic power stations increases considerably because of the low cost installation, Thus, it is necessary to develop new control strategies for the operation and control management of the PV system's integrated to the grid so that improving the quality, the energy efficiency and the reliability of the system [11, 12]. The grid voltage parameters, such as frequency, phase angle, and amplitude are important information for many areas of electrical system applications, as the supply converters connected to the grid $[13,14]$. The inverters dedicated to photovoltaic systems have to respond rapidly in milliseconds because of the variation of solar irradiation [15]. These electronic converters can be connected to single-phase or three-phase power supply system [16]. The three-phase inverters are recommended to ensure a better balance of power between phases. The PV systems can be effectively controlled to improve the functioning of the system at the common coupling point (CCP) with the recent advances of the power electronics.

The inverters used in PV system connected to the grid can be connected in series. However, due to the PQ injection, some problems appear at the level of the injected currents such as mains voltage is deformed. If the grid side converter is not synchronized with the grid, an important transient current can appear at the time of connection, which will damage the system. To realize the synchronization process, precise information on the amplitude, phase, and frequency of the grid voltage is necessary. The synchronization methods are classified into two categories: the open-loop and closed-loop methods [17]. The zero-crossing detection method is an example of the open-loop method, these methods of open-loop have a slow dynamic response and are sensitive to frequency deviations. The closed-loop methods include the conventional phase-locked loop (PLL) and are more popular because of their robustness and accuracy. The current developments on the grid synchronization techniques are mainly based on estimation methods. Among these methods, the adaptive filters, such as the generalized second-order generalized integrator (SOGI) were proposed in [18] to estimate the grid voltage parameters.

The SOGI is more adapted to a single-phase application, an improved version by SOGI is proposed for dual SOGI (DSOGI) for grid synchronization of three-phase system under deformed grid voltage conditions [13]. The DSOGI technique uses two SOGI filters and this causes an increase in response time. Afterwhich, a technique of estimation and synchronization of the PV system connected to the grid by the application of self tuning filter (STF) reported in [19], the STF was designed for a grid-connected PV system to extract the fundamental component of current and voltage under a deformed and unbalanced grid voltage. Various documents were reported for the synchronization of the grid PV system in deformed and unbalanced grid voltage conditions cited in $[20,21]$. The main power quality issues associated with the integration of renewable in the grid are the voltage harmonics across the local load and the current harmonics injected into the grid by the inverter $[18,22]$. The harmonics are signals present in the original signal with frequencies that are an integer multiple of the fundamental frequency of the original signal. The total harmonic distortion (THD) is a power quality index that indicates the content of harmonics in a distorted waveform [23]. The THD of the tensions and the currents for the system connected to grid must be lower than $5 \%$ [24].

In this paper, an efficient method of PV system power injection in a three-phase microgrid with different voltage conditions is illustrated. In this method, the control approach is to maximize the transfer of the active power. For this, the DC voltage is controlled to sufficient and non-fluctuating levels so that maximum power is injected under better conditions into the grid side inverter. The voltage imbalance and harmonic content in the grid voltage system cause distortions to current injected. Therefore, synchronization with the network is an important feature to control the voltage converter, but, the deformed grid, voltage leads to a synchronization failure. That is to say the detection of the positive-sequence component at a fundamental frequency under unbalanced and distorted conditions is essential. In this case we try to propose a new strategy of direct power control based on the virtual flux (VF_DPC), By means of a SOGI associated with a STF the synchronization with the fundamental grid is kept and guarantee that the currents injected in the three-phase network emulate the wished sinusoidal forms even when the grid voltage is no longer ideal.

\section{MODELING OF THE PV SYSTEM CHAIN}

In the proposed energy system as shown in Figure 1, the PV system is connected to the network through a boost converter (DC/DC) to adjust the DC bus voltage to sufficient and non-fluctuating levels so that we inject all the power in better conditions through the inverter connected network. 


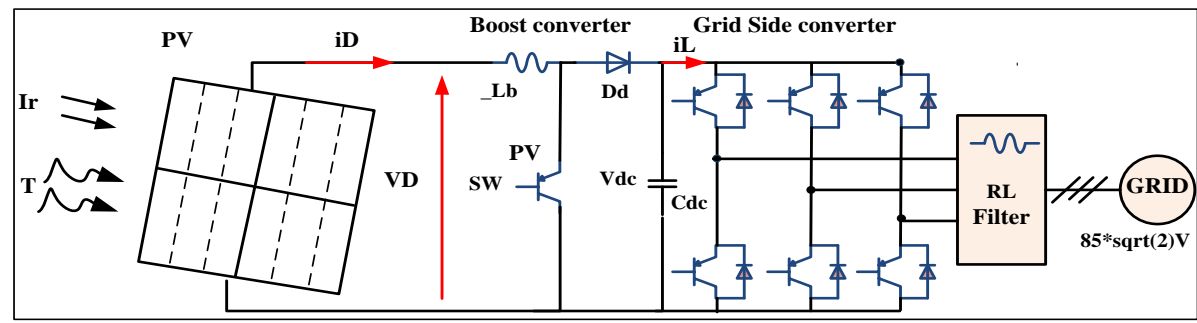

Figure 1. Circuit diagram of the grid-connected inverter

\subsection{Control of DC/DC boost converter}

An arrangement of cells connected in series is necessary to increase the level of DC voltage at the output of some renewable sources (for example PV systems), but in many cases, this is not enough to ensure that the inverter is working properly. Thus; a DC/DC boost converter must be built and used with electronic semiconductor devices, an inductor and a capacitor in parallel with a resistor [25]. The photovoltaic generator is connected to the input of the boost converter and its input voltage is controlled so that the photovoltaic generator delivers the maximum power to its output terminals. The main objective of the boost converter is to convert the variable input DC voltage, in different functioning conditions, to an appropriate constant continuous voltage. The intermediate circuit voltage can be maintained constant at the reference value by controlling the duty cycle of the converter. The control structure of the DC-DC boost converter is based on the use of the PI regulator to maintain the DC link voltage at the reference value, as shown in Figure 2.

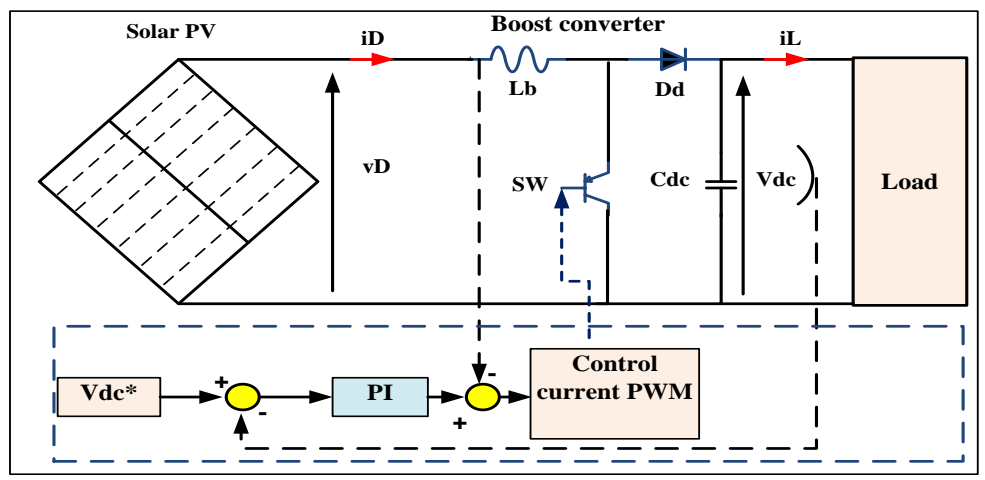

Figure 2. DC-DC boost-converter control structure

\subsection{Control of the grid side converter}

\subsubsection{Modeling of the three-phase grid side converter}

The converter can be expressed in a reference $a-b-c$ by (1):

$$
\left[e_{a} e_{b} e_{c}\right]=-R\left[i_{s a} i_{s b} i_{c}\right]-L \frac{d_{i}}{d t}\left[i_{s a} i_{s b} i s_{c}\right]+\left[V_{a} V_{b} V_{c}\right]
$$

where, $\mathrm{L}$ and $\mathrm{R}$ are the inductance and resistance of the chokes respectively. $\mathrm{e}_{\mathrm{a}}, \mathrm{e}_{\mathrm{b}}, \mathrm{e}_{\mathrm{c}}, \mathrm{i}_{\mathrm{sa}}, \mathrm{i}_{\mathrm{sb}}, \mathrm{i}_{\mathrm{sc}}$ are the electrical grid voltages and currents, $\mathrm{V}_{\mathrm{a}}, \mathrm{V}_{\mathrm{b}}, \mathrm{V}_{\mathrm{c}}$ are the $\mathrm{AC}$ side voltages of the converter as shown in Figure 3. The AC rectifier's voltages $V_{a}, V_{b}, V_{c}$ are defined as (2):

$$
\left\{V_{a}=\frac{V_{d c}}{3}\left(2 S_{a}-S_{b}-S_{c}\right) V_{b}=\frac{V_{d c}}{3}\left(-S_{a}+2 S_{b}-S_{c}\right) V_{C}=\frac{V_{d c}}{3}\left(-S_{a}-S_{b}+2 S_{c}\right)\right.
$$

$S_{a}, S_{b}$ and $S_{c}$ are the switching states of the converter. The relationship between the AC side rectifier currents $i_{s a}, i_{s b}, i_{s c}$ and the DC bus voltage $V_{d c}$ can be written as:

$$
C_{d c} \frac{d V_{d c}}{d t}=S_{a} i_{a}+S_{b} i_{b}+S_{c} i_{c}-i_{L}
$$




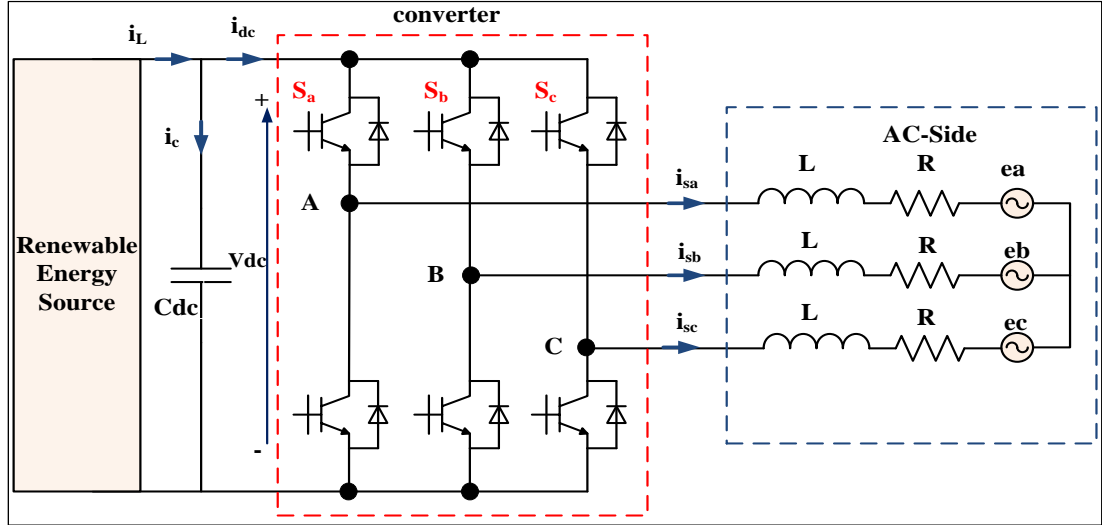

Figure 3. Modeling of the three-phase grid side converter

\subsubsection{Virtual flux based direct power control (VF_DPC)}

In the VF concept, the virtual AC motor is assumed from the behavior of the mains voltages at the AC side coupling pulse with the series of an inductance and an equivalent resistance R. Consequently, $\mathrm{L}$ and $\mathrm{R}$ are equivalent to the leak inductance and the AC motor stator resistance, respectively [26]. The control of the active power (Pref) and the reactive power (Qref) are compared with the values of the estimated active and reactive powers (Pes and Qes) by hysteresis controllers. Moreover, the digitized output signals (SP) and $(\mathrm{SQ})$ and the vector position $\operatorname{VF}(\theta \varphi)$ allow selecting the vector of the corresponding voltage according to the switching table shown in Table 1 defined in [27]. The vector of $\operatorname{VF} \varphi_{\alpha \beta}=\left[\varphi_{\alpha} \varphi_{\beta}\right]^{\mathrm{T}}$ can be estimated from the integration of the vector of network voltages $e_{\alpha \beta}=\left[e_{\alpha} e_{\beta}\right]^{\mathrm{T}}$ as indicated in (4):

$$
\left\{\begin{array}{l}
\varphi_{s \alpha}=\int\left(V_{s \alpha}+R_{s}\right) d t+L \frac{d_{i \alpha}}{d t} \\
\varphi_{s \beta}=\int\left(V_{s \beta}+R_{s \beta}\right) d t+L \frac{d_{i}}{d t}
\end{array}\right.
$$

There is a change in the level of the sectors; sector 1 is replaced by sector 4 , see Figure.4. These sectors may be expressed as follows: $(N-5) \frac{\pi}{6}<\theta_{N}<(N-4) \frac{\pi}{6}$, with: $V \mathrm{~s}(\alpha \beta)$ the output voltage of the inverter in reference $\alpha, \beta$.

The active and reactive powers can be estimated as (5):

$$
\left\{P_{e s}=\omega\left(\varphi_{s \alpha} * i_{s \beta}-\varphi_{s \beta *} i_{s \alpha}\right) Q_{e s}=\omega\left(\varphi_{s \alpha} * i_{s \alpha}+\varphi_{s \beta *} i_{s \beta}\right)\right.
$$

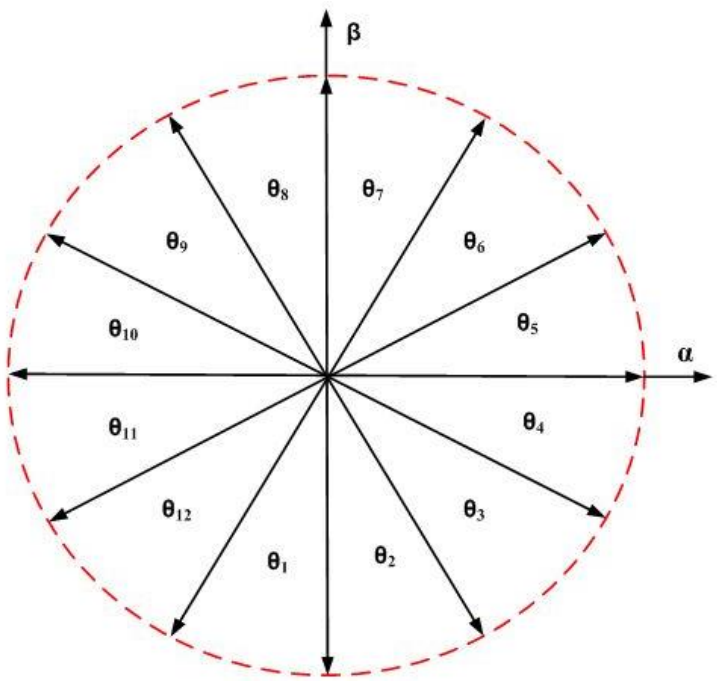

Figure 4. Virtual flux plane 12 sectors 
Figure 5 shows the overall configuration of the direct power control without voltage sensor based on the virtual flux.

Table 1. Switching table

\begin{tabular}{cccccccccccccc}
\hline $\mathrm{Sp}$ & $\mathrm{Sq}$ & $\theta_{1}$ & $\theta_{2}$ & $\theta_{3}$ & $\theta_{4}$ & $\theta_{5}$ & $\theta_{6}$ & $\theta_{7}$ & $\theta_{8}$ & $\theta_{9}$ & $\theta_{10}$ & $\theta_{11}$ & $\theta_{12}$ \\
\hline \multirow{2}{*}{1} & 0 & $\mathrm{~V}_{5}$ & $\mathrm{~V}_{6}$ & $\mathrm{~V}_{6}$ & $\mathrm{~V}_{1}$ & $\mathrm{~V}_{1}$ & $\mathrm{~V}_{2}$ & $\mathrm{~V}_{2}$ & $\mathrm{~V}_{3}$ & $\mathrm{~V}_{3}$ & $\mathrm{~V}_{4}$ & $\mathrm{~V}_{4}$ & $\mathrm{~V}_{5}$ \\
& 1 & $\mathrm{~V}_{3}$ & $\mathrm{~V}_{4}$ & $\mathrm{~V}_{4}$ & $\mathrm{~V}_{5}$ & $\mathrm{~V}_{5}$ & $\mathrm{~V}_{6}$ & $\mathrm{~V}_{6}$ & $\mathrm{~V}_{1}$ & $\mathrm{~V}_{1}$ & $\mathrm{~V}_{2}$ & $\mathrm{~V}_{2}$ & $\mathrm{~V}_{3}$ \\
\multirow{2}{*}{0} & 0 & $\mathrm{~V}_{6}$ & $\mathrm{~V}_{1}$ & $\mathrm{~V}_{1}$ & $\mathrm{~V}_{2}$ & $\mathrm{~V}_{2}$ & $\mathrm{~V}_{3}$ & $\mathrm{~V}_{3}$ & $\mathrm{~V}_{4}$ & $\mathrm{~V}_{4}$ & $\mathrm{~V}_{5}$ & $\mathrm{~V}_{5}$ & $\mathrm{~V}_{6}$ \\
& 1 & $\mathrm{~V}_{1}$ & $\mathrm{~V}_{2}$ & $\mathrm{~V}_{2}$ & $\mathrm{~V}_{3}$ & $\mathrm{~V}_{3}$ & $\mathrm{~V}_{4}$ & $\mathrm{~V}_{4}$ & $\mathrm{~V}_{5}$ & $\mathrm{~V}_{5}$ & $\mathrm{~V}_{6}$ & $\mathrm{~V}_{6}$ & $\mathrm{~V}_{1}$ \\
\hline
\end{tabular}

Note: $v 1(100), v 2(110), v 3(010), v 4(011), v 5(001), v 6(101), v 0(000), v 7(111)$

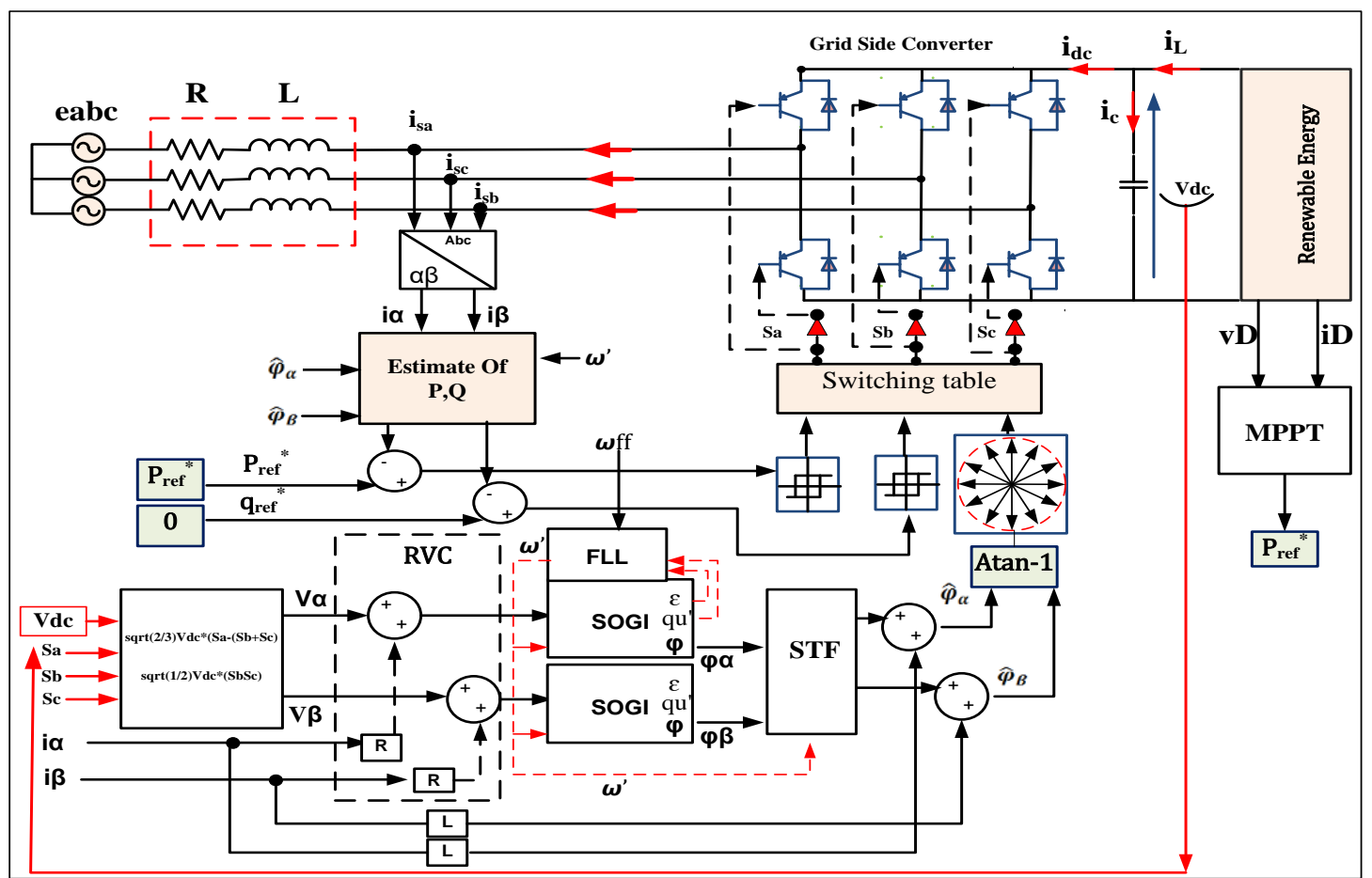

Figure 5. Direct power control scheme based on a virtual flux (VF_DPC)

\section{SOGI-FLL FLUX ESTIMATION}

\subsection{Structure of SOGI}

The structure of the SOGI is indicated in Figure 6, the first output ( $\left.v^{\prime}\right)$ of the SOGI is in phase with the input $(\mathrm{u})$ with the same amplitude, the second output (qu') is in quadrature with the same amplitude. The third output $\varphi$ represents the integral of the input $v$. The three outputs can, then, be used to calculate the quantities and phase of the input $(\mathrm{v})$. The gain $(\mathrm{K})$ is the damping factor of the filter, a high-value gain gives a fast response but can affect the filter precision and a low-value gain can result in a very long transient response. The optimal value of the gain $\mathrm{K}$ is sqrt (2) [28].

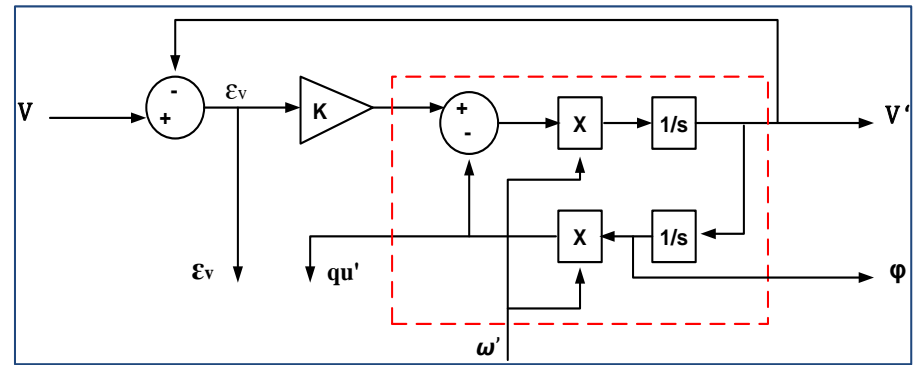

Figure 6. Functional diagrams of SOGI 


$$
\begin{aligned}
& D(S)=\frac{v^{\prime}}{v}(S)=\frac{K \omega \prime s}{s^{2}+K \omega^{\prime} s+\omega^{\prime 2}} \\
& Q(S)=\frac{q u^{\prime}}{v}(S)=\frac{K \omega^{\prime 2}}{s^{2}+K \omega^{\prime} s+\omega^{\prime 2}}
\end{aligned}
$$

From (7), the structure of the SOGI-QSG is derived. We can conclude that the quadrature output signal qv corresponds to the integral VF, the signal filtered by the bandwidth $\mathrm{v}$. This signal can be defined as "Frequency VF".

\subsection{Frequency locked loop}

The structure of the frequency-locked loop (FLL), shown in Figure 7, can be used to measure the angular frequency of the input signal $\mathrm{v}$ (in this case, $\omega^{\prime}$ is the estimated angular frequency of the input signal), without using trigonometric functions and facilitating their implementation in conventional microcontrollers [29]. The FLL allows adapting the SOGI input frequency to the signal filtering frequency. The SOGI account is a good solution for estimating the virtual flux under a disturbed grid.

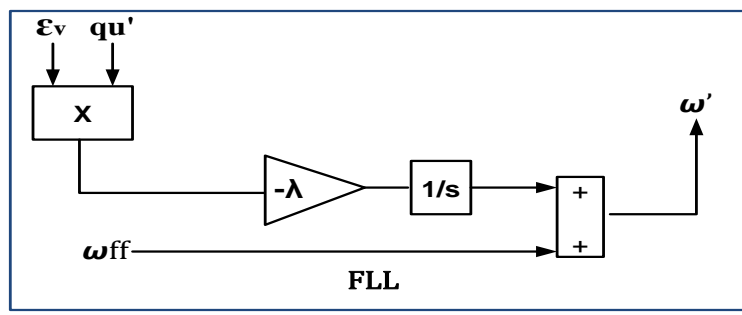

Figure 7. Functional diagrams of FLL

\section{STRUCTURE FOR THE VF ESTIMATION WITH POSITIVE SEQUENCE SEPARATION}

The proposed integrator will be used to track the components of the positive sequence in the deferential condition of the input voltage. Consequently, the positive VF components obtained from an STF Self-tuning filter is used in the VF-DPC algorithm to estimate the active and reactive power (P-es) and (Q-es), shown in Figure 8. The mathematical model is developed for the first time by Song Hong-Scok, the relationship between the input and output quantities have an integral effect [30] as shown in (8).

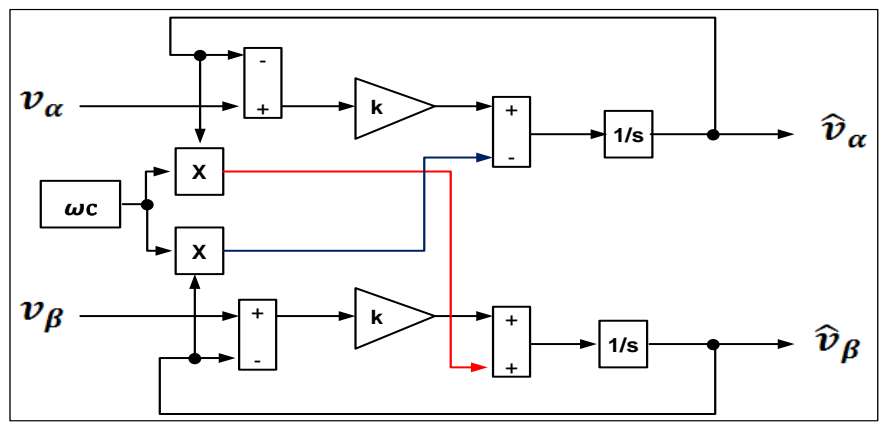

Figure 8. Functional diagrams of the STF

$$
\hat{v}_{\alpha \beta}(s)=e^{j \omega_{c} t} \int e^{-j \omega_{c} t} v_{\alpha \beta}(t) \cdot d t
$$

where $\omega_{c}$ : cutting frequency. After Laplace transformation of (8), The (9) is derived [29].

$$
H(s)=\frac{\hat{v}_{\alpha \beta}(s)}{v_{\alpha \beta}(s)}=K \cdot \frac{(s+1)+j \omega_{c}}{(s+K)^{2}+\omega_{c}^{2}}
$$


The transfer function (9), proves that the output signal $\hat{v}_{\alpha \beta}$ is in phase with the input signal $v_{\alpha \beta}$. Moreover, if we draw the Bode diagram of this transfer function we will find similarities with a bandpass filter. Suppose now that we add a new K constant in expression (9). Then we got (10) as:

$$
H(s)=\frac{\hat{v}_{\alpha \beta}(s)}{v_{\alpha \beta}(s)}=K \cdot \frac{(s+1)+j \omega_{c}}{(s+K)^{2}+\omega_{c}^{2}}
$$

Writing in complex form we obtain:

$$
\left\{\hat{v}_{\alpha \beta}(s)=\hat{v}_{\alpha}(s)+j \hat{v}_{\beta} v_{\alpha \beta}(s)=v_{\alpha}(s)+j v_{\beta}\right.
$$

According to the axes $(\alpha-\beta)$, the expressions linking the components $\hat{v}_{\alpha \beta}$ at the output of the STF to the input components $v_{\alpha \beta}$ are as follows:

$$
\begin{aligned}
& \hat{v}_{\alpha}=K \cdot \frac{(s+K)+\omega_{c}}{(s+K)^{2}+\omega_{c}^{2}} v_{\alpha}(s)-\frac{K * \omega_{c}}{(s+K)^{2}+\omega_{c}^{2}} v_{\beta}(s) \\
& \hat{v}_{\beta}=\frac{K * \omega_{c}}{(s+K)^{2}+\omega_{c}^{2}} v_{\alpha}(s)+K \cdot \frac{(s+K)+\omega_{c}}{(s+K)^{2}+\omega_{c}^{2}} v_{\beta}(s)
\end{aligned}
$$

Expressions (12) and (13) can be written as follows:

$$
\begin{aligned}
& \hat{v}_{\alpha}=\left(\frac{K}{s}\left[v_{\alpha}(s)-\hat{v}_{\alpha}(s)\right]-\frac{\omega_{c}}{s} \hat{v}_{\beta}(s)\right) \\
& \hat{v}_{\beta}=\left(\frac{K}{s}\left[v_{\beta}(s)-\hat{v}_{\beta}(s)\right]+\frac{w_{c}}{s} \hat{v}_{\alpha}(s)\right)
\end{aligned}
$$

\section{SIMULATION RESULTS}

The control system was simulated in MATLAB/Simulink environment. The main electrical parameters of the power circuit and the control data are presented in Table 2. The parameters of the panel used in this work are presented in Table 3, knowing that 8 panels were used, four of which each are connected in series forming two groups connected in parallel.

Table 2. Simulation parameters

\begin{tabular}{lc}
\hline \multicolumn{1}{c}{ Parameters } & Value \\
\hline Switching period Ts & $20 \mu \mathrm{S}$ \\
The resistance of reactors $\mathrm{R}$ & $0.56[\Omega]$ \\
Inductance of reactors L & $19.5[\mathrm{mH}]$ \\
dc-bus capacitor C & $1100 \mu \mathrm{F}$ \\
Load resistance $R L$ & $68.6[\Omega]$ \\
The line to line ac voltage $E$ and frequency $f$ & $85 \mathrm{~V} \mathrm{RMS}, 50 \mathrm{~Hz}$ \\
dc-bus voltage $V d c$ & $180 \mathrm{~V}$ \\
K ok STF & 20 \\
K of SOGI & $\mathrm{Sqrt}(2)$ \\
$\lambda$ & -100 \\
\hline
\end{tabular}

Table 3. Panel setting

\begin{tabular}{lc}
\multicolumn{2}{c}{ Table 3. Panel setting } \\
\hline \multicolumn{2}{c}{ Parameters } \\
\hline $\mathrm{q}$ & $1.602 \mathrm{e}-19$ \\
$\mathrm{~K}$ & $1.3854 \mathrm{e}-23$ \\
Short-circuit current temperature coefficient & $4.58 \mathrm{~A}$ \\
Vg & 17.5 \\
Cells series number Ns & 36 \\
Short-circuit current Isc_T1 & 4.95 \\
Open-circuit voltage Voc_T1 & 21.9 \\
Reference temperature T1 & $273+25$ \\
\hline
\end{tabular}

\subsection{Test 1: maximum power generation injected}

In the first case, we tested the performance of the PV system connected to the network for a change of illumination in the following way $1000(\mathrm{~W} / \mathrm{m}), 800(\mathrm{~W} / \mathrm{m}), 600(\mathrm{~W} / \mathrm{m}), 900(\mathrm{~W} / \mathrm{m})$. The purpose of the algorithm is to track the maximal power of the system. Figure 9 shows the system's response for a progressive change of the illumination, $1000(\mathrm{~W} / \mathrm{m})$ at $800(\mathrm{~W} / \mathrm{m})$ at $600(\mathrm{~W} / \mathrm{m})$ at $900(\mathrm{~W} / \mathrm{m})$. We see in Figures 9 (a) and (b) that the voltage VD and the current (id) are checked according to the MPPT strategy and can be better regulated to reach the current optimum. Figure 9 (c) shows that the DC (Vdc) voltage reaches its $180 \mathrm{~V}$ reference quickly. Figure 9 (d) shows that the DC current (iL) at the output of the boost converter is controlled according to the MPPT strategy. The boost converter control proves its ability to offer a fast response time and to follow the reference voltage regardless of the solar radiation variation. 

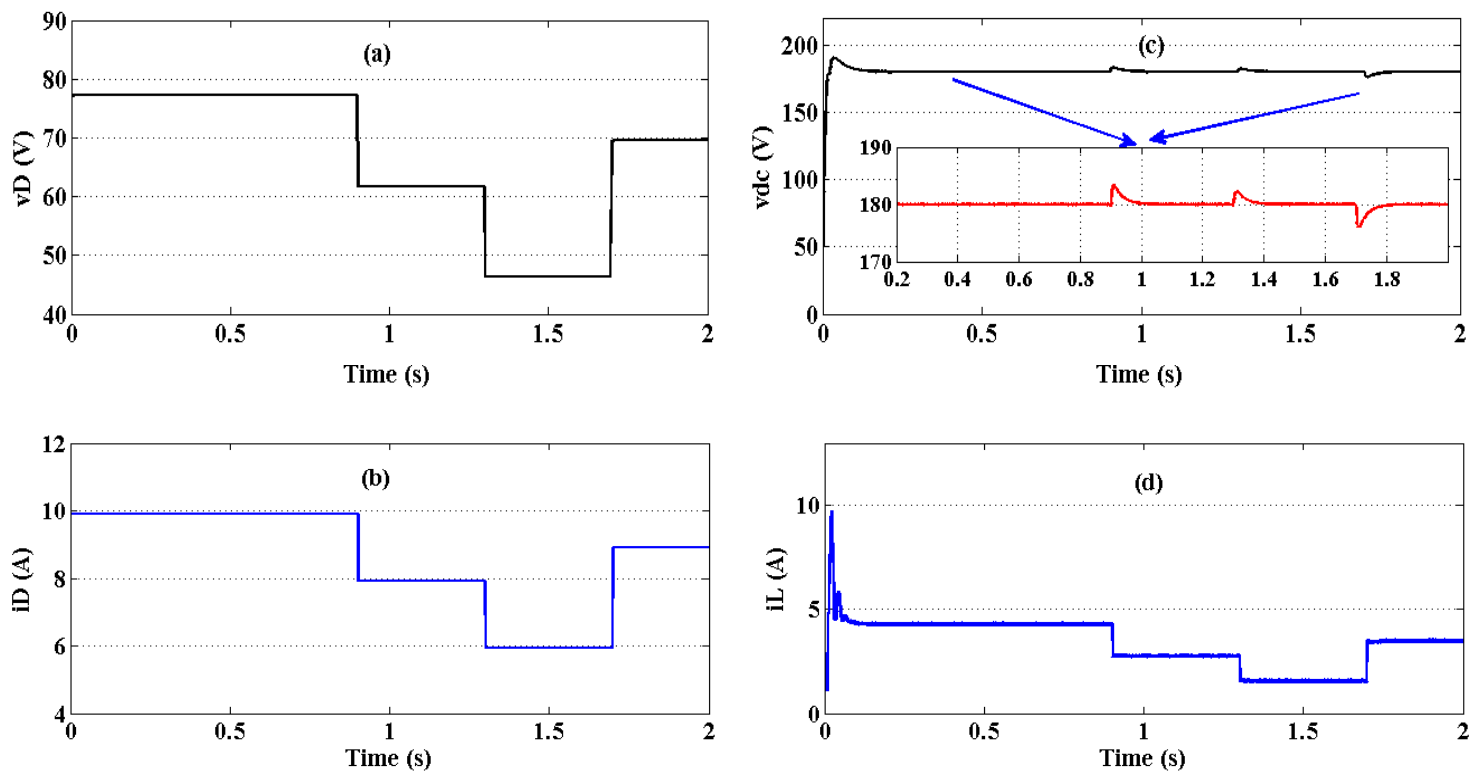

Figure 9. The response of the boost converter for a variation of illumination, (a) Input boost converter voltage, (b) Input boost converter current, (c) Output boost converter voltage Vdc, (d) Output boost converter current iL

Figures 10 (a) and 10 (b) shows that the power injected into the network is controlled to track the reference power imposed by the MPPT algorithm that is what we need all the power generated by the panels is injected into the network with success. Figures 10 (c) and 10 (d) show that the active and reactive powers estimated (controlled) are identical to the measured power, this indicates that the applied VF_DPC has very high performance. Figure 11 shows that the currents injected in the grid are controlled to be sinusoidal and balanced with a very low distortion rate that varies from $0.68 \%$ at $3.08 \%$, it depends on the quantity of energy injected. The injected currents Increase and decrease because of the variation of solar radiation. We can easily observe that the dynamic response for a sudden change in radiation level is preferable for the proposed system.
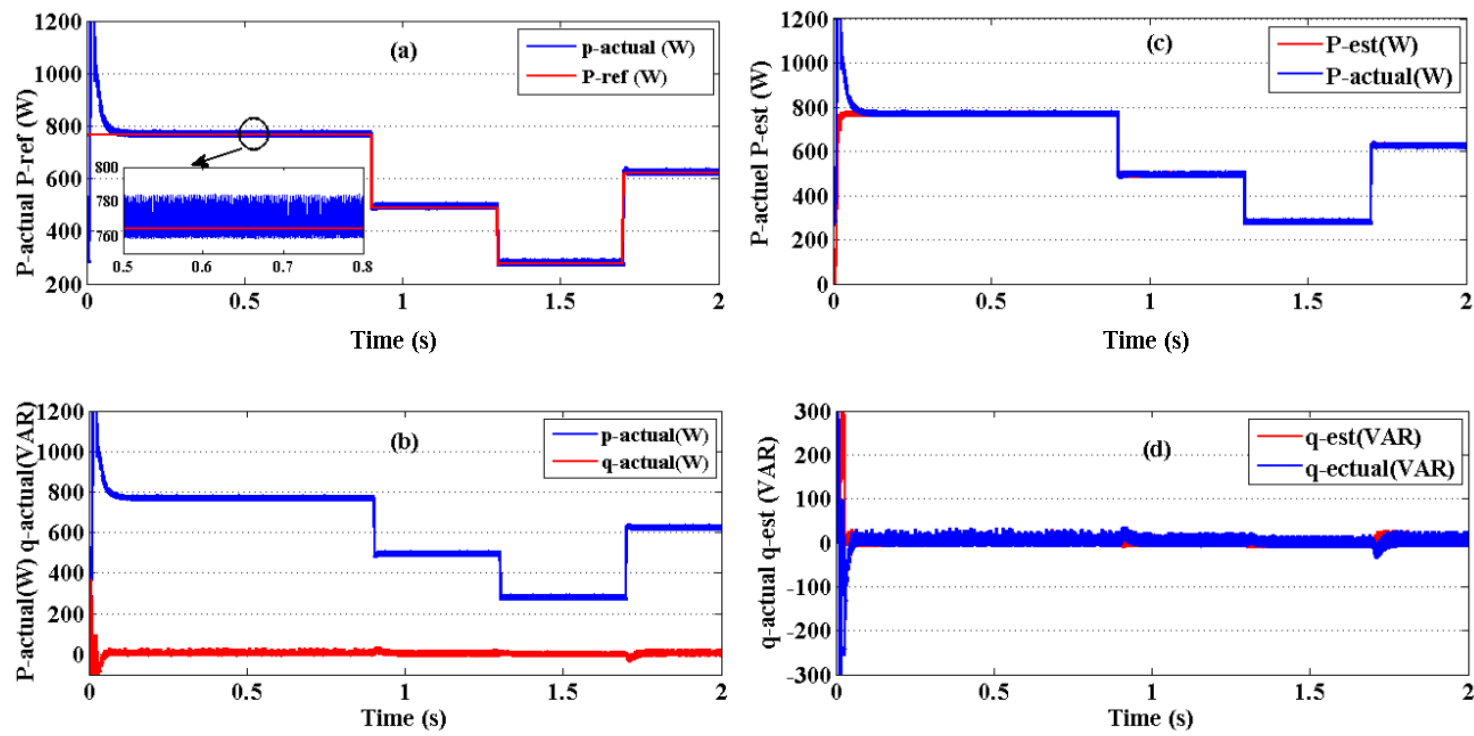

Figure 10. Performance of the VF_DPC in a balanced and non-distorted grid during the various periods of solar radiation, (a) Active measured power at the power reference, (b) Actual active and reactive power,

(c) Active power estimated at the measured power, (d) Reactive power estimated at the measured reactive power 


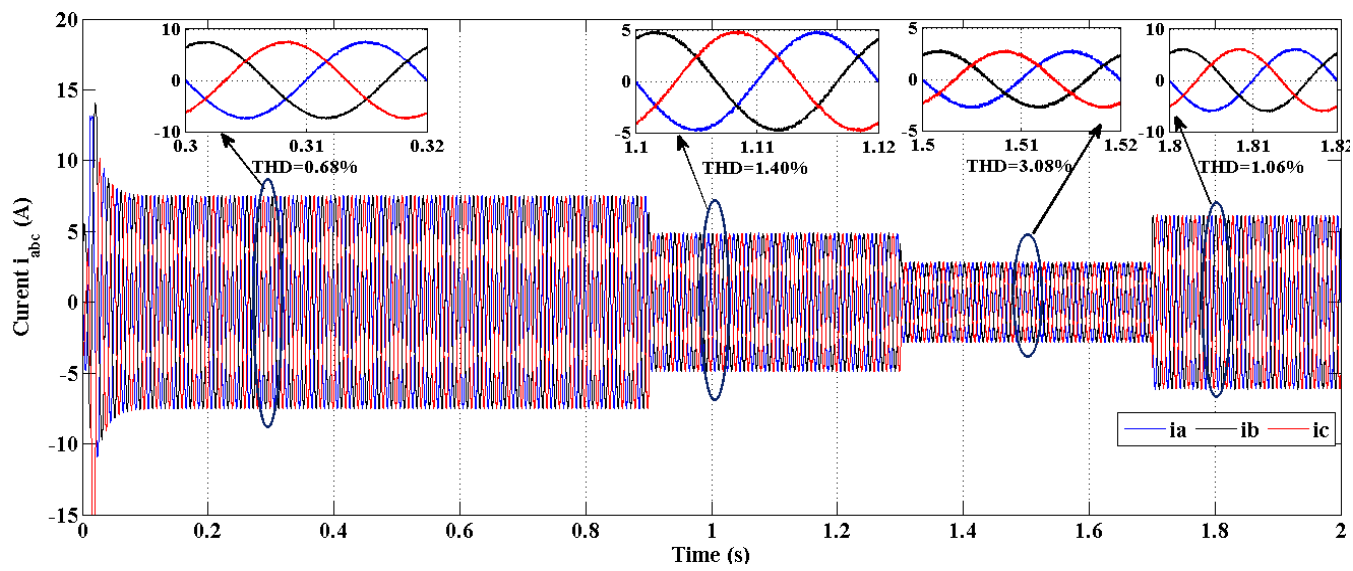

Figure 11. The response of injected currents in a balanced and non-distorted network

\subsection{Test 2: responses in various grid voltage conditions}

In this case, we tested the performance of the PV system for illumination of $1000(\mathrm{~W} / \mathrm{m})$ connected to the unbalanced and distorted network. We apply three conditions of mains voltage, First, the grid voltages are balanced and sinusoidal, then we create an imbalance of $30 \%$ on the phase ea, In the following interval, We apply an imbalance of $25 \%$ to the phase ea and a $25 \%$ harmonic of order $7^{\text {th }}$ on three phases. Finally, we create at the same time a harmonic of $25 \%$ of order $5^{\text {th }}$ and $7^{\text {th }}$ on three phases. Figure 12 shows the performances of VF_DPC proposed under unbalanced and distorted mains voltages. We can observe that the currents injected into the grid are sinusoidal and balanced even for deformed and unbalanced voltages. The negative sequence and the low order harmonic components of the currents are also controlled at zero. The THD of the network currents is limited according to the IEEE-519 standard harmonic, it is clearly seen that grid currents can become sinusoidal. The study is conducted to evaluate the performance of the system under different voltage conditions.

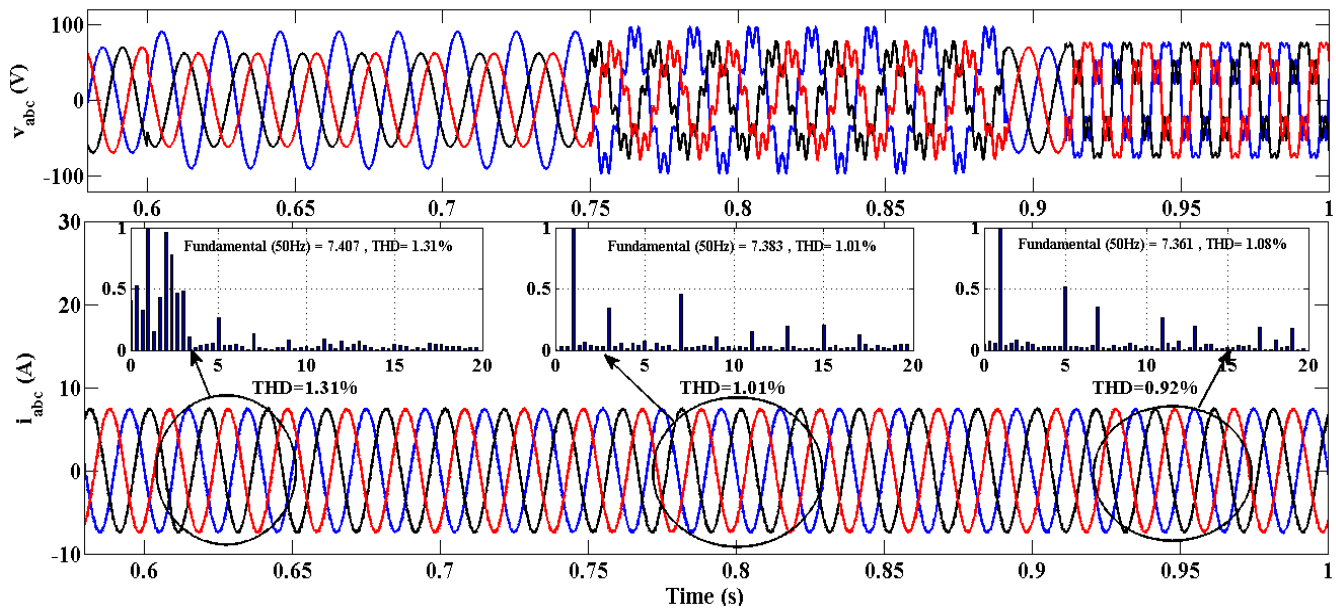

Figure 12. The response of currents injected into a grid under different voltage conditions

Figure 13 (a) shows that the flux estimated by this integrator remains stable in all cases studied. Figures 13 (b) and (c) show that the estimated power and DC bus voltage are kept very close to their references. The oscillations of $(2 \omega)$ around the rated values shown on the actual power Figures 13 (c) and the DC voltage result from the negative part of the input voltages. The presence of the 5th harmonic creates a pulsation content at the frequency $(6 \omega)$ in the voltage output of the DC and the real power, on the other hand, the harmonic of the $7^{\text {th }}$ order creates a pulse content at the frequency $(-6 \omega)$, this is shown by the disappearance of the oscillations in the active power and the DC voltage in the case of a network deformed by the $5^{\text {th }}$ and $7^{\text {th }}$ harmonic (same percentage). Figure 13 (d) show that the active and reactive powers estimated (controlled). 


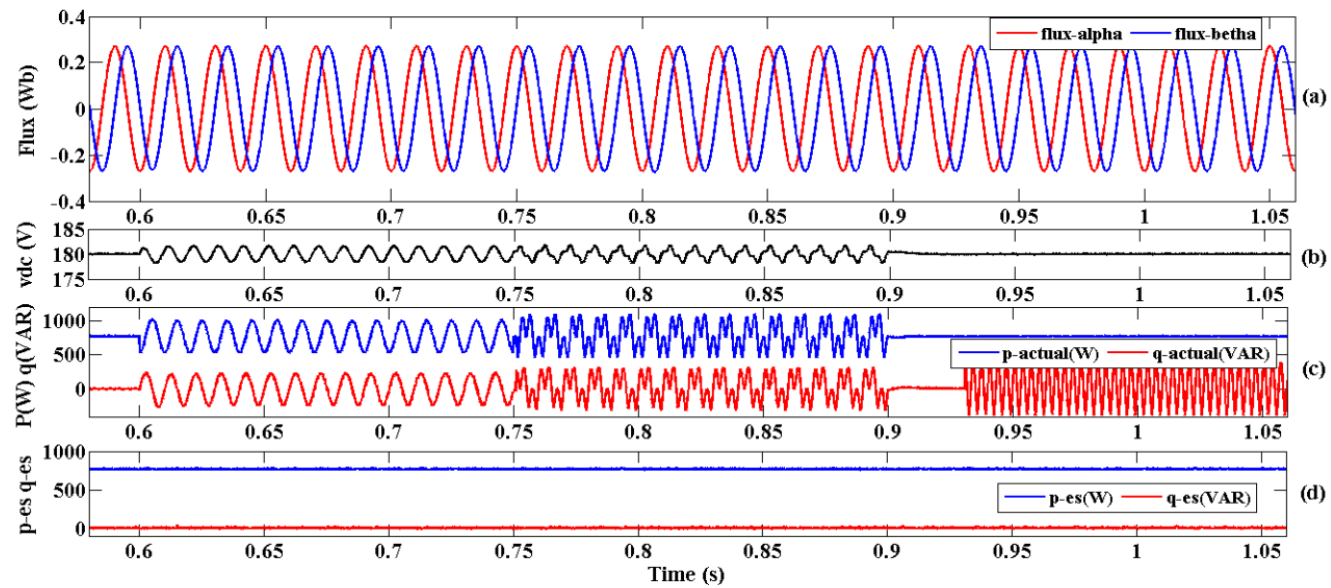

Figure 13. Results for the proposed observer VF_DPC, (a) Estimated flux, (b) Vdc voltage, (c) Actual active and reactive power, (d) The powers estimated controlled

\section{CONCLUSION}

This paper presented a new control scheme for a PV system based on the synchronization and injection of a maximum of PV energy into a three-phase micro-grid. The synchronization approach is developed to attenuate the harmonics of the load current, extract the maximum PV energy and inject it into the grid. In this article, synchronization and control of the grid-side inverter are based on VF-DPC without line sensor, using a SOGI associated with a STF. This combination helped in handling all sorts of problems resulted by distorted array voltages providing an efficient synchronization of the PV system. The simulation results showed that the scheme proposed in this work presents greater stability. The currents injected in the three-phase network are kept in sinusoidal forms even when the grid voltage is no longer ideal. The negative sequence and the low order harmonic components of the currents are also controlled at zero. The THD of the network currents is limited according to the IEEE-519 standard harmonic. The algorithm given in this paper presents a reliable way to generate a free harmonic source to the network.

\section{REFERENCES}

[1] S. Kouro, J. I. Leon, D. Vinnikov, and L. G. Franquelo, "Grid-connected photovoltaic systems: An overview of recent research and emerging PV converter technology," in IEEE Industrial Electronics Magazine, vol. 9, no. 1, pp. 47-61, March 2015.

[2] T. A. Huld, M. Suri, R. P. Kenny, and E. D. Dunlop, "Estimating PV performance over large geographical regions," Conference Record of the Thirty-first IEEE Photovoltaic Specialists Conference, Lake Buena Vista, FL, USA, pp. 1679-1682, 2005.

[3] N. Okada, S. Yamanaka, H. Kawamura, H. Ohno, and H. Kawamura, "Energy loss of photovoltaic system caused by irradiance and incident angle," 3rd World Conference onPhotovoltaic Energy Conversion, 2003, Proceedings of, Osaka, vol. 2, pp. 2062-2065, 2003.

[4] H. Patel and V. Agarwal, "MATLAB-based modeling to study the effects of partial shading on PV array characteristics," in IEEE Transactions on Energy Conversion, vol. 23, no. 1, pp. 302-310, March 2008.

[5] W. Xiao, N. Ozog, and W. G. Dunford, "Topology study of photovoltaic interface for maximum power point tracking," in IEEE Transactions on Industrial Electronics, vol. 54, no. 3, pp. 1696-1704, June 2007.

[6] B. Subudhi and R. Pradhan, "A comparative study on maximum power point tracking techniques for photovoltaic power systems," in IEEE Transactions on Sustainable Energy, vol. 4, no. 1, pp. 89-98, Jan. 2013.

[7] R. Faraji, A. Rouholamini, H. R. Naji, R. Fadaeinedjad, and M. R. Chavoshian, "FPGA-based real time incremental conductance maximum power point tracking controller for photovoltaic systems," in IET Power Electronics, vol. 7, no. 5, pp. 1294-1304, May 2014.

[8] S. Kamalakkannan and D. Kirubakaran,"Solar energy system based impedance-source inverter for grid connected system," International Journal of Applied Power Engineering, vol. 7, no. 2, pp. 129-138, August 2018.

[9] Tsao-Tsung Ma,"Power quality enhancement in micro-grids using multifunctional DG inverters," In Proceedings of the international multiconference of engineers Comp. sent., Hong Kong, vol. 2, 2012.

[10] Pragya Nema, R. K. Nema, and Saroj Rangnekar,"A current and future state of art development of hybrid energy system using wind and PV-solar: a review," Renewable and Sustainable Energy Reviews, vol. 13, no. 8, pp. 2096-2103, 2009.

[11] W El-Khattam and M. M. A Salama, "Distributed generation technologies: definitions and benefits," Electric Power Systems Research, vol. 71, no. 1, pp. 119-128, 2004. 
[12] O. Alonso, P. Sanchis, E. Gubia, and L. Marroyo, "Cascaded H-bridge multilevel converter for grid connected photovoltaic generators with independent maximum power point tracking of each solar array," IEEE 34th Annual Conference on Power Electronics Specialist, 2003. PESC '03., Acapulco, Mexico, vol. 2, pp. 731-735, 2003.

[13] P. Rodríguez, A. Luna, R. S. Muñoz-Aguilar, I. Etxeberria-Otadui, R. Teodorescu, and F. Blaabjerg, "A stationary reference frame grid synchronization system for three-phase grid-connected power converters under adverse grid conditions," in IEEE Transactions on Power Electronics, vol. 27, no. 1, pp. 99-112, Jan. 2012.

[14] A Rahab, H Benalla, and F Senani,"Improved virtual flux direct power control of three phase PWM rectifier using SOGI-FLL estimator under disturbed voltage conditions," International Journal of Applied Power Engineering, vol. 8, no. 1, pp. 34-42, 2019.

[15] Lucas S. Xavier, Allan F. Cupertino, and Heverton A. Pereira, " Ancillary services provided by photovoltaic inverters: Single and three-phase control strategies," Computers and Electrical Engineering, vol. 70, pp. 102-121, 2018.

[16] T. Kerekes, R. Teodorescu, M. Liserre, C. Klumpner, and M. Sumner, "Evaluation of three-phase transformerless photovoltaic inverter topologies," in IEEE Transactions on Power Electronics, vol. 24, no. 9, pp. 2202-2211, 2009.

[17] A. Timbus, M. Liserre, R. Teodorescu, and F. Blaabjerg, "Synchronization methods for three phase distributed power generation systems-An overview and evaluation," 2005 IEEE 36th Power Electronics Specialists Conference, Recife, pp. 2474-2481, 2005.

[18] Anthoula Menti, Thomas Zacharias, and John Milias-Argitis, "Harmonic distortion assessment for a single-phase grid-connected photovoltaic system," Renewable Energy, vol. 36, no. 1, pp. 360-368, 2011.

[19] S. Swain and B. Subudhi, "A New grid synchronisation scheme for a three-phase PV system using self-tuning filtering approach," in IET Generation, Transmission \& Distribution, vol. 11, no. 14, pp. 3557-3567, 2017.

[20] F. A. S. Neves, M. Carrasco, F. Mancilla-David, G. M. S. Azevedo, and V. S. Santos, "Unbalanced Grid Fault Ride-Through Control for Single-Stage Photovoltaic Inverters," in IEEE Transactions on Power Electronics, vol. 31, no. 4, pp. 3338-3347, 2016.

[21] A. El-Naggar and I. Erlich, "Control approach of three-phase grid connected PV inverters for voltage unbalance mitigation in low-voltage distribution grids,"IET Renewable Power Generation, vol. 10, no. 10, pp. 1577-1586, 2016.

[22] S. Chattopadhyay, M. Mitra, and S. Sengupta, "Electric power quality," Springer, 2011.

[23] IEEE Application Guide for IEEE Std 1547(TM), "IEEE standard for interconnecting distributed resources with electric power systems," in IEEE Std 1547.2-2008, pp.1-217, 2009.

[24] "Photovoltaic (PV) systems characteristics of the utility interface," IEC 61727 International Standard, 2004.

[25] D. Lauria and M. Coppola, "Design and control of an advanced PV inverter," Solar En., vol. 110, pp. 533-542, 2014.

[26] M. Malinowski, M. P. Kazmierkowski, S. Hansen, F. Blaabjerg, and G. D. Marques, "Virtual-flux-based direct power control of three-phase PWM rectifiers," IEEE Transactions on Industry Applications, vol. 37, no. 4, pp. 1019-1027, 2001.

[27] A. Bouafia, J.P. Gaubert, and A. Chaoui, "Direct power control scheme based on disturbance rejection principle for three-phase PWM AC/DC converter under different input voltage conditions," J. Electrical Systems, vol. 8, no. 4, pp. 367-383, 2012.

[28] J. A. Suul, A. Luna, P. Rodríguez, and T. Undeland, "Virtual-flux-based voltage-sensor-less power control for unbalanced grid conditions," in IEEE Transactions on Power Electronics, vol. 27, no. 9, pp. 4071-4087, 2012.

[29] P. Rodriguez, A. Luna, M. Ciobotaru, R. Teodorescu, and F. Blaabjerg, "Advanced grid synchronization system for power converters under unbalanced and distorted operating conditions," IECON 2006-32nd Annual Conference on IEEE Industrial Electronics, Paris, pp. 5173-5178, 2006.

[30] Hong-Seok Song, "Control scheme for PWM converter and phase angle estimation algorithm under-voltage unbalanced and/or sag condition," Ph.D dissertation, Electron. and Electr. Eng., POSTECH Univ., Pohang, 2001. 